\title{
Espaço híbrido e o protagonismo da hashtag
}

\author{
Hybrid space and the protagonism of the hashtag \\ El espacio híbrido y el protagonismo del hashtag
}

\author{
Júlia Lourenço Costa ${ }^{1}$ \\ Universidade Federal de São Carlos - UFSCar \\ juliajlc@gmail.com
}

\begin{abstract}
RESUMO: Neste artigo procuraremos compreender o funcionamento dos processos linguístico-discursivos que operam como força motriz dos movimentos sociais e políticos atuais marcados pelo ajustamento aos dispositivos e novos suportes comunicacionais. A partir do mirante da Linguística, e, mais especificamente, das teorias do discurso (PAVEAU, 2017; 2017a), temos como interesse principal promover uma reflexão científica acerca da relação estabelecida entre a tecnologia implicada no desenvolvimento dos meios de comunicação e a política, tendo como foco o uso da linguagem dos movimentos sociais digitais. Abordaremos, sobretudo, a hashtag procurando compreendê-la como impulsionadora da maior percepção do espaço híbrido (CASTELLS, 2017), que se estabelece entre o ambiente digital e o espaço urbano (DIAS, 2016; 2018). $\mathrm{O}$ corpus considerado para este texto foi delimitado pelos discursos produzidos em torno da \#elenão que, produzida e circulada em 2018 contra Bolsonaro, retoma o espaço social.
\end{abstract}

Palavras-chave: Discurso digital; Hashtag; Espaço híbrido.

ABSTRACT: In this article will seek to understand the functioning of linguisticdiscursive processes that operate as the driving force of current social and political movements marked by adjustment to the devices of new communication media. From the stand point of Linguistics, and more specifically from discourse theories (PAVEAU, 2017; 2017a), we have as main interest to promote a scientific reflection about the relationship established between technology involved in the development of the media and politics, focusing on the use of language in digital social movements. We will especially address the hashtag, determining as a corpus the discourses produced around \#nothim, seeking to understand it as a driver of the greater perception of hybrid space (CASTELLS, 2017), which is established between the digital environment and urban space (DIAS, 2016; 2018). The corpus considered for this text was delimited by the discourses produced around \#nothim which, produced and circulated against Bolsonaro in 2018, retakes the social space.

Keywords: Digital discourse; Hashtag; Hybrid space.

RESUMEN: En este artículo buscaremos comprender el funcionamiento de los procesos lingüístico-discursivos que operan como motor de los actuales movimientos sociales y políticos marcados por el ajuste a los dispositivos de los

\footnotetext{
${ }^{1}$ Pesquisadora de Pós-Doutorado na Universidade Federal de São Carlos e bolsista da Fundação de Amparo à Pesquisa do Estado de São Paulo (UFSCar - FAPESP 2017/12792-0).
} 
nuevos medios de comunicación. Desde la atalaya de la Lingüística, y más concretamente desde las teorías del discurso (PAVEAU, 2017; 2017a), tenemos como principal interés promover una reflexión científica sobre la relación que se establece entre la tecnología implicada en el desarrollo de los medios de comunicación y la política, centrándose en el uso del lenguaje en los movimientos sociales digitales. Abordaremos especialmente el hashtag, buscando entenderlo como impulsor de la mayor percepción del espacio híbrido (CASTELLS, 2017), que se establece entre el entorno digital y el espacio urbano (DIAS, 2016; 2018). El corpus considerado para este texto fue delimitado por los discursos producidos en torno de la \#elenó que, producida y circulada en 2018, retoma el espacio social. Palabras clave: Discurso digital; Hashtag; Espacio híbrido. 


\section{A manifestação política digital}

O avanço tecnológico que funda a cibercultura extrapola a questão técnica e propõe novas atitudes da sociedade contemporânea, promovendo, para além do desenvolvimento dos próprios aparelhos, a transformação na forma de interação humana e também no seu modo de expressão. A internet, de acordo com Lévy (1999), é um dos principais novos meios de comunicação, sendo encarada como parte das tecnologias digitais e funcionado enquanto infraestrutura das comunicações no ciberespaço. Nela, são criados diversos ambientes virtuais de interação, que reconstroem as relações intersubjetivas, agora mediadas pela máquina.

O desenvolvimento dos meios de comunicação tem relação imbricada com a política, uma vez que se configuram enquanto espaço soberano de contato entre os líderes políticos e os/as cidadãos/ãs - democratizando a comunicação, expondo opiniões e debatendo temas relevantes e polêmicos para o Estado, por exemplo (CASTELLS, 2017). Nesse sentido, o impacto da evolução tecnológica aliada ao desenvolvimento da própria mídia é sentido também - e inclusive - no campo político.

Apesar da discussão acirrada entre cientistas políticos e estudiosos da comunicação estes exagerando sobre a importância da mídia na política e aqueles ignorando a sua influência e/ou participação -, é necessário que também os pesquisadores das ciências da linguagem se apresentem cada vez mais ao debate; afinal, concomitante à transformação nos formatos da informação (desde o rádio, a televisão, até a internet na contemporaneidade), há também a composição de novos recursos linguístico-discursivos.

Nesse ínterim, os movimentos sociais têm cada vez mais ganhado força de circulação no ciberespaço, que funciona como amplificador on-line das causas já debatidas off-line. $\mathrm{O}$ poder da internet está, em certa medida, relacionado à capacidade do comportamento humano de ser refletido no ambiente virtual, daí o surgimento do termo "cibercultura", como relação entre sociedade, cultura e ambiente eletrônico digital.

$\mathrm{Na}$ internet, as diversas instituições discursivas produzem e circulam sentido e é possível verificar contemporaneamente a proliferação das manifestações relacionadas aos movimentos sociais que - assim como a própria sociedade - estão em constante transformação. O ciberativismo, que nasce a partir da relação dos movimentos sociais com as novas tecnologias, tem contribuído não só na divulgação das variadas causas sociais, políticas e econômicas, mas na própria determinação destes movimentos reivindicatórios.

De acordo com Castells (2001), as lutas sociais foram historicamente marcadas por movimentos sociais que mantinham certa cadeia hierárquica alinhada aos valores 
verticalizados do processo de industrialização. Por outro lado, o que se assiste hoje, com o ciberativismo é certa e circunscrita horizontalização das lutas contemporâneas, que passam a ter uma estrutura marcada pelo acesso mais democrático proporcionado pela rede.

A internet se configura como ferramenta para as lutas sociais contemporâneas e é concebida como espaço potencial de expressão e participação genuinamente democrática (DEIBERT, 2000). Tal ferramenta viabiliza a união e a mobilização das variadas comunidades discursivas ${ }^{2}$, além da promoção horizontalizada das informações, que passam a ser difundidas de lugares discursivos cada vez menos marcados pela hierarquia das relações sociais e políticas.

Castells (2017) defende que a manifestação dos movimentos sociais na internet está alinhada em âmbito global, uma vez que é possível observar o ciberativismo como protagonista em diferentes culturas, ambientes institucionais e diferentes níveis de desenvolvimento. $\mathrm{O}$ ponto nodal entre as diversas manifestações está assentado numa crise no sistema político vigente, desencadeada pela insatisfação da sociedade em torno de questões sociais e políticas primordiais.

O sociólogo salienta, ainda, que as redes sociais digitais reconstroem o espaço público, criando novas comunidades que ocupam também o espaço urbano com propostas de mudança social, uma vez que o controle do espaço significa, em certa medida, o controle de vidas. Butler, sobre esse aspecto, afirma que "o que vemos quando os corpos se reúnem em assembleia nas ruas [...] é o exercício de aparecer, uma demanda corporal por um conjunto de vidas mais vivíveis (BUTLER, 2019, p. 31). O espaço público ocupado pelos movimentos sociais que se iniciam na internet torna-se, portanto, um espaço mais político, de manifestação dos ideais e dos desejos da sociedade.

Estabelecemos, portanto, como objetivo principal deste artigo, compreender como a hashtag, enquanto elemento discursivo concebido no ambiente digital, funciona como condensador da escala estabelecida entre os modos de vida on-line e off-line. O movimento entre o urbano e a internet estabelece uma percepção acurada do espaço híbrido (CASTELLS, 2015) que habitamos e é nosso interesse analisar os processos linguístico-discursivos, e também técnicos, que fazem com que este espaço seja também concretizado na e por meio da linguagem.

\footnotetext{
${ }^{2}$ Uma comunidade discursiva engloba aquele que produz certo discurso, mas também os que o fazem circular, reproduzindo e validando sua enunciação. A comunidade discursiva é "[...] um grupo ou a organização de grupos no interior dos quais são produzidos, gerados os textos que dependem da formação discursiva" (MAINGUENEAU, 1997, p. 56).
} 


\section{O movimento social brasileiro \#elenão}

O presente trabalho parte da concepção de que os movimentos sociais são caracterizados pela "ação coletiva realizada em vista de um objetivo, cujo resultado, em caso de sucesso e como em caso de fracasso, transforma os valores e as instituições da sociedade" (CASTELLS, 2001). Dessa maneira, é possível abordarmos os feminismos ${ }^{3}$ enquanto movimento social heterogêneo, uma vez que reivindica, sucintamente, a mudança dos valores patriarcais na sociedade, isto é, questiona “o status quo patriarcal, caracterizado pela combinação interseccional gênero-raça-classe-sexualidade e - devemos acrescentar - idade e plasticidade" (TIBURI, 2019, p. 43).

As diversas reivindicações feministas podem ser compreendidas enquanto movimento social na medida em que lutam coletivamente por um direito: o direito da equidade entre homens e mulheres, buscando superar, portanto, as "contradições fundamentais da sociedade, nascidas tanto do desenvolvimento do capitalismo como da persistência até hoje da dominação masculina, que se exprime na divisão social e sexual, por exemplo" (HIRATA et al., 2009, p. 152).

O protesto e o empenho das mulheres em ocupar o ambiente cibernético são também uma das formas de reivindicar as lutas dos feminismos, pois tratam de dar voz às mulheres através dos meios de comunicação contemporâneos, dentre eles, principalmente, a internet. Se considerarmos que grande parte das ciências da tecnologia e da informação são formadas por homens ${ }^{4}$, esse aspecto da luta feminina também por este espaço é sublinhado. $\mathrm{O}$ desenvolvimento e a utilização de novas tecnologias esteve - e permanece ${ }^{5}$-, tradicionalmente, sob o domínio masculino, uma vez que histórico-culturalmente estão alinhadas ao masculino qualificações como inteligência e ativismo público e as lutas feministas também protestam em relação a estas funções.

Ocupando os espaços digitais, as mulheres reivindicam seu espaço social e contribuem com a luta feminista de outrora: da primeira onda (do final século XIX ao início século XX),

\footnotetext{
${ }^{3}$ Para mais detalhes, consultar Olivera, Mello e Rigolin (2020).

${ }^{4}$ Compreendemos que "o feminismo como coletivo de luta de mulheres só se manifesta na segunda metade do século XX. Essas lutas partem do reconhecimento das mulheres como específica e sistematicamente oprimidas, na certeza de que as relações entre homens e mulheres não estão inscritas na natureza, e que existe a possibilidade política de transformação. [...] Falar de 'movimentos feministas' permite designar sob uma mesma denominação as diversas formas de movimentos de mulheres, o feminismo liberal ou 'burguês', o feminismo radical, as mulheres marxistas ou socialistas, as mulheres lésbicas, as mulheres negras e todas as dimensões categoriais dos movimentos atuais" (FOUGEYROLLAS-SCHWEBEL, 2009, p. 144-145).

${ }^{5}$ Há diversos grupos em todo o mundo que discutem a relação da mulher com a criação e gerenciamento de novas tecnologias. Citamos alguns: Rail Girls, Women who code, PyLadies, Code Girls, MariaLab, Women TechMakers, Womoz, Meninas Digitais, Mulheres na tecnologia, Technovation, dentre outros
} 
em que eram requeridos direitos iguais a homens e mulheres centrando no direito ao voto; da segunda onda (até 1970), que se preocupou, em linhas gerais, com a sexualidade, a violência e o mercado de trabalho; e a terceira onda (1990), marcada pelo questionamento interno ao próprio movimento, tendo como ponto nevrálgico as noções de feminilidade e gênero aliadas à reflexão sobre as minorias sociais (ALVES; PITANGUY, 1991; VAN ENIS, 2012; PINSKY; PEDRO, 2018).

Nossos objetos específicos de reflexão estão ancorados no movimento feminista brasileiro intitulado \#elenão, que

foram manifestações populares lideradas por mulheres que ocorreram em diversas regiões do Brasil e do mundo, tendo como principal objetivo protestar contra a candidatura à presidência da República do deputado federal Jair Bolsonaro. As manifestações ocorreram no dia 29 de setembro de 2018 , e se tornaram o maior protesto já realizado por mulheres no Brasil e a maior concentração popular durante a campanha da eleição presidencial no Brasil em 2018. As manifestações começaram a ser organizadas nas redes sociais, principalmente no grupo "Mulheres contra Bolsonaro" no Facebook. Os protestos foram motivados pelas declarações misóginas do candidato e também por suas ameaças à democracia. Movimentos sociais, grupos feministas e partidos também apoiaram e participaram das manifestações ${ }^{6}$.

A partir deste movimento social brasileiro, teceremos observações, ancoradas nas teorias do discurso, sobre como a hashtag, enquanto elemento característico do ambiente digital, migra para o espaço urbano encarnando reivindicações e, por meio do processo de iconização do texto, retorna ao espaço ao qual inicialmente pertencia. Esse trânsito da hashtag entre on-line e off-line distorce as fronteiras antes estabelecidas entre os dois espaços, caracterizando cada vez mais a possibilidade de um espaço híbrido (CASTELLS, 2017).

\section{\#Elenão e a ocupação do espaço urbano por meio da linguagem}

A expressão humana em superfícies coletivas não é novidade, pensemos nas inscrições antigas nas cavernas, por exemplo. A street art (grafite ou pichação urbana) é elaborada no século XX, quando o termo "inscrição urbana" passou a ser usado com mais intensidade, a fim de englobar os dois gêneros supracitados.

De acordo com Correa (2016, p. 20), "as inscrições urbanas podem ser consideradas como uma forma contemporânea de uma prática humana histórica", isto é, como fenômeno

\footnotetext{
${ }^{6}$ Disponível em: 〈https://pt.wikipedia.org/wiki/Movimento_Ele_N\%C3\%A3o〉. Acesso em: 10 out. 2020.
} 
característico da contemporaneidade que se inscreve no próprio desenvolvimento humano. Dessa maneira, para pensar as inscrições urbanas não podemos olvidar sua inserção em determinado momento histórico, no qual conflui o aumento da população nas metrópoles, a criação das mídias, a cultura de massa, além do spray e do pincel atômico (CORREA, 2016, p. 20). Defende-se, portanto, que as inscrições urbanas têm origem a partir dos anos 1960.

Dois fatores contribuem para a prática do grafite e da pichação: o acesso aos materiais e o espaço propício para a atividade. De um lado, os materiais usados (spray e pincel atômico, supracitados) derivam da necessidade de rapidez, uma vez que a prática ainda é considerada ilegal em muitos espaços. De outro, as mídias exteriores, que usam muros e vagões de trem com a finalidade de comunicar, também tiveram grande influência no desenvolvimento da prática.

Entre prática e produto é necessário considerar, de uma perspectiva linguística, o nível da enunciação. No enunciado que abrange a manifestação da \#elenão não se encontra autoria demarcada, pois o objetivo é criar o efeito de voz coletiva, a "voz da cidade", "a voz do povo", "a voz das mulheres", que grita e se expressa contra o sistema vigente. Tanto a enunciação quanto o enunciado da inscrição urbana são coletivos.

No célebre maio de 1968 em Paris, por exemplo, os protestos criaram seu próprio meio de expressão. Insatisfeitos com o moralismo familiar, com o sistema educacional normativo e com o sistema político vigente, os jovens franceses, munidos de sprays, imprimiram versos pela cidade: "É proibido proibir", "A imaginação toma o poder", "As paredes têm ouvidos, os ouvidos têm paredes", por exemplo (CORREA, 2016).

A principal diferença entre a chamada pichação, derivada das tags americanas, e o grafite é marcada pelo apelo estético. Enquanto a pichação tem como objetivo a quantidade, isto é, espalhar-se pela cidade, o grafite passou a valorizar as formas e cores na produção visual (sendo até posteriormente considerado arte e compondo nas galerias). O grafite procurava, portanto, valorizar também o plano da expressão, não se esquecendo do plano do conteúdo, enquanto a pichação se manteve atenta mais ao conteúdo projetado.

O grafite brasileiro foi diretamente influenciado pelo movimento de Paris. Em 1960 e 1970 frases estampavam as capitais do país, tais como "Abaixo a ditadura" ou "Diretas já", enfatizando o plano do conteúdo a partir de diferentes temáticas. A autonomia da inscrição urbana no Brasil tem seu auge com a criação, por Rui Amaral e John Howard, do Beco do Batman, na Vila Madalena em São Paulo, espaço que tem como ideal contribuir para o processo de afirmação do grafite como arte. 
De acordo com Correa (2016, p. 57), é possível observar "uma característica comum a todos esses artistas urbanos: a profunda integração do uso do espaço, do suporte e da obra pictural". O pesquisador afirma, ainda, que é possível observar que "a linguagem pictórica vai tomando o lugar da linguagem verbal, ou seja, a palavra cede lugar à imagem" (CORREA, 2016, p. 58). Dessa maneira, segundo ele, a carência do desenvolvimento visual é compensada pela elaboração no plano do conteúdo e no plano da expressão verbal (CORREA, 2016, p. 100).

A finalidade das inscrições políticas é informar e engajar o enunciatário - o cidadão transeunte - fazendo com que ele reconheça os slogans políticos. Nestas inscrições, a prática exige maior visibilidade para comunicar-se com o grande público, pois o engajamento depende da intensa repetição. Daí a preferência por muros e lugares públicos bastante visíveis na cidade e o uso de spray para maior eficácia e rapidez. Ainda segundo o semioticista (CORREA, 2016, p. 176), no plano da expressão visual, o uso de letras bastão com pouca elaboração formal e o uso de frases curtas davam conta da necessária agilidade do ato e da comunicação direta com o público. A relação entre suporte material e suporte formal é delimitada, portanto, pela prática excessivamente arriscada.

\section{Hashtag ativismo: \#elenão nos muros da cidade}

Durante a efervescência do movimento \#elenão, em 2018, foi possível observar a inscrição deste enunciado também pelos muros da cidade. Essa prática, com este elemento específico, a \#elenão contra Bolsonaro, foi retomada em variados contextos políticos no Brasil, retomando a memória discursiva do momento inicial. A fim de enriquecer o debate, propomos também alguns exemplos desta hashtag sendo usada durante a pandemia (março 2020 até os dias atuais). Os novos usos da hashtag \#elenão muitas vezes vem acompanhados da \#ForaBolsonaro. Ambas ocupam tanto as redes sociais, como agora as projeções nos prédios de diversas cidades brasileiras e até as máscaras produzidas para se proteger dos riscos de infecção e espalhamento do vírus.

Do ponto de vista linguístico e mais especificamente discursivo, adotado neste artigo, duas questões centrais detêm nosso interesse: a) o uso do símbolo hashtag \#, nativo da internet, e a sua difusão nas inscrições urbanas; b) a propagação, nas redes sociais, das inscrições urbanas que contêm a hashtag, novamente na internet, por meio de fotografias. 
Estamos aí diante de dois fenômenos que inserem a inscrição urbana também no universo digital, uma por meio da utilização do símbolo hashtag (a cerquilha \#) que dialoga com um tipo específico de produção tecnodiscursiva e outra pela sua difusão de fotografias na rede. De acordo com Paveau (2017, p. 197),

a hashtag é um segmento de linguagem precedido pelo símbolo \#, utilizado originalmente na rede Twitter, mas adaptada a outras plataformas como Facebook, principalmente. Essa associação a transforma numa tag clicável, inserida manualmente no tweet e permite acessar a um fio que reúne o conjunto de enunciados que contém a hashtag.

A própria autora afirma que a hashtag saiu rapidamente da rede social na qual foi criada, o Twitter, e invadiu outros gêneros digitais (não é raro nos depararmos com hashtags em reportagens publicadas nas versões digitais dos meios de comunicação, por exemplo). Além disso, é intrigante observar a saída do símbolo hashtag do universo digital e o seu uso, por exemplo, em publicidades, produtos a serem comercializados, cartazes durante as manifestações ou estampando os muros da cidade. Segundo Paveau (2017, p. 198-199),

a hashtag rapidamente se tornou um elemento familiar da paisagem gráfica e digital contemporânea. Acontece, cada vez mais, encontrar as hashtags fora da internet ou em contextos nos quais ela não é mesmo clicável, numa mensagem eletrônica, um texto, ou em determinados sites, onde elas são integradas linguisticamente nos enunciados, sem sua função hipertextual.

Observemos alguns breves exemplos da migração da hashtag do ambiente digital para o ambiente urbano, tanto em pichações (Figura 1), quanto em grafites (Figura 2), no corpo (Figura 3), nos cartazes e adesivos durante as manifestações (Figura 4) bem como nas projeções em prédios da cidade (Figura 5) e máscara de proteção facial (Figura 6): 
Júlia Lourenço Costa. Espaço híbrido e o protagonismo da hashtag.

Figura 1 - grafite ${ }^{7}$

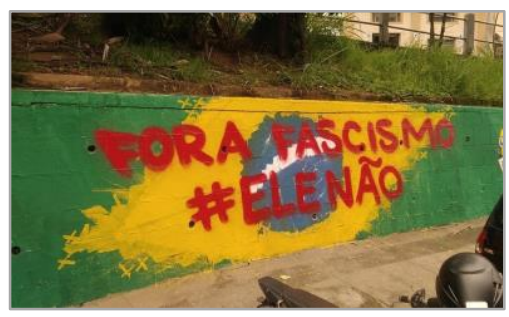

Figura 4 - cartazes $^{10}$

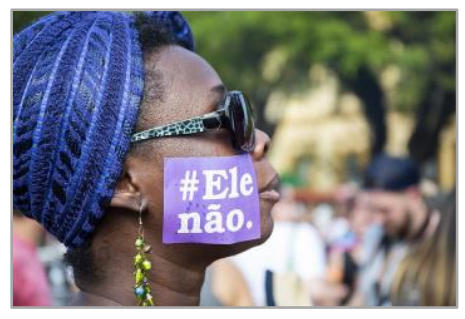

Figura 2 - pichação ${ }^{8}$

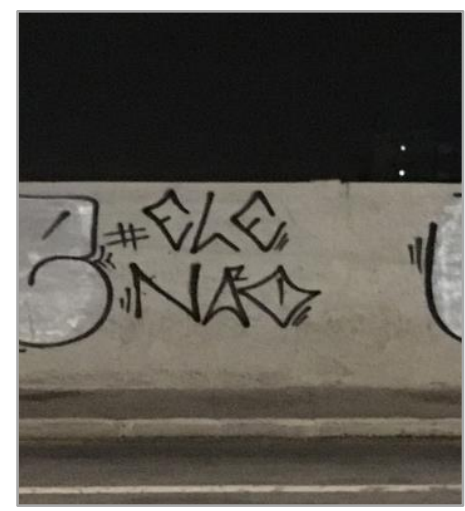

Figura 5 - projeção ${ }^{11}$

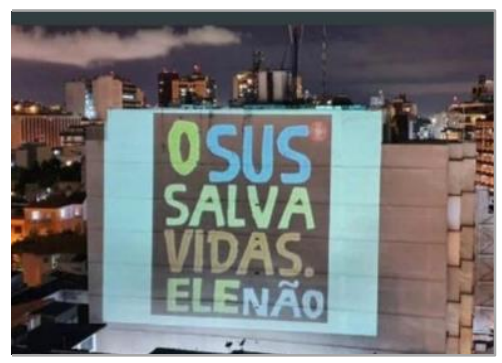

Figura 3 - pintura corporal ${ }^{9}$

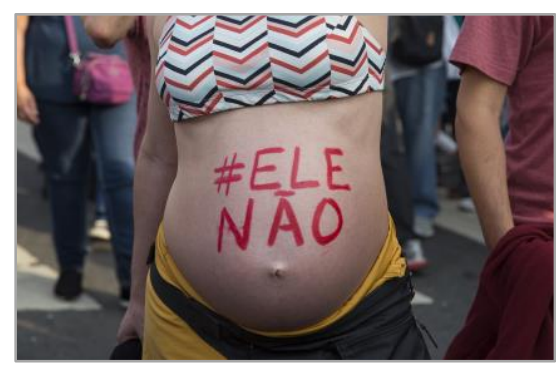

Figura 6 - máscara ${ }^{12}$

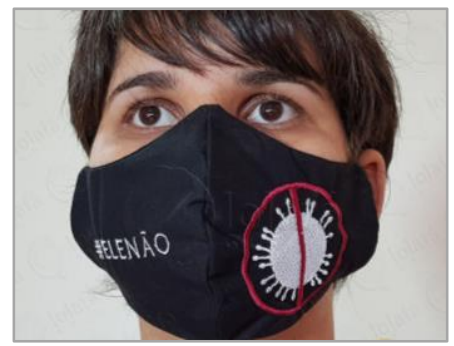

Quando todos estes elementos apresentados passam a incorporar elementos nativos do meio digital, tal como a hashtag, eles podem também ser incorporados no seio do hashtagativismo, isto é, o ativismo digital que se mobiliza em torno de determinada reivindicação por meio da circulação de hashtags. Essa incorporação ocorre de uma forma mais encarnada, quando materialmente inscritos nos muros da cidade, mas também de uma forma mais digital e menos encarnada, quando fotografados e reenviados ao ambiente digital.

Apesar de não nos aprofundarmos nesta direção, salientamos que o profícuo conceito de conecticidade, proposto por Dias (2018), procura refletir sobre a relação entre estes espaços. Estamos, portanto, alinhados ao pensamento da pesquisadora quando ela afirma que é importante

\footnotetext{
${ }^{7}$ Disponível em: <https://www.webstagram.me/media/BpcS_pmhnIS>. Acesso em: 10 out. 2020.

${ }^{8}$ Disponível em: <http://www.twipu.com/umcaum>. Acesso em: 10 out. 2020.

${ }^{9}$ Disponível em: <https://ponte.org/pela-democracia-mulheres-contra-bolsonaro-vao-as-ruas-gritar-ele-nao/>. Acesso em: 10 out. 2020.

10 Disponível em: <https://www.globaljustice.org.uk/news/2018/oct/28/nothim-not-now-not-ever-statementelection-jair-bolsonaro>. Acesso em: 10 out. 2020.

${ }^{11}$ Ainda que neste caso da figura 5 o símbolo da hashtag não esteja presente (\#), somente o segmento verbal (ele não), defendemos que por meio da memória discursiva, toda mobilização social em torno da \#elenão está concretizada. Disponível

em: <https://www.facebook.com/MidiaNINJA/photos/a.1289900797834729/2030691870422281/?type=3〉. Acesso em: 30 out. 2020.

12 Disponível em: <https://www.elo7.com.br/mascara-tecido-kit-c-16-md97-bordada-elenao/dp/1237336〉. Acesso em: 10 jan. 2021.
} 
levar em conta a constituição do espaço urbano pelo digital. Não tomar a cidade e o espaço urbano como já significados pela tecnologia, mas os considerar em seu movimento de significação pela tecnologia digital, naquilo que escapa a qualquer estabilização. No acontecimento da tecnologia no urbano (DIAS, 2018, p. 109).

\section{A inserção da inscrição urbana na web}

Seguindo na direção dos percursos da hashtag entre o urbano e o digital, podemos afirmar que as inscrições urbanas dialogam com o discurso ativista digital na medida em que também circulam on-line, isto é, quando são fotografados os segmentos verbais e visuais que compõem o grafite e/ou pichação e essas fotografias passam a circular na web. A partir do processo chamado por Paveau (2017) de iconização do texto, essas inscrições urbanas se inscrevem também no ciberespaço.

O processo de iconização do texto está assentado na percepção visual do texto, isto é, a imagem se apropria da linguagem articulada verbal a reconfigurando de maneira icônica. $\mathrm{O}$ texto fotografado se torna portanto um texto iconizado, apreendido em determinado momento e estabilizado de acordo com as convenções da fotografia; ele perde sua capacidade de articulação e se torna uma representação daquilo que ele era inicialmente.

De acordo com Paveau, "nas redes sociais se desenvolve cada vez mais essa prática de captura de tela de um texto ou da fotografia do texto" (PAVEAU, 2017, p. 309), isto é, o internauta fotografa o segmento verbal e o compartilha como imagem. Observemos a seguir como esse processo foi mobilizado pelo movimento \#elenão a partir de alguns recortes de textos de inscrições urbanas que passaram a circular na internet ${ }^{13}$ :

Figura 7 - Website ${ }^{14}$

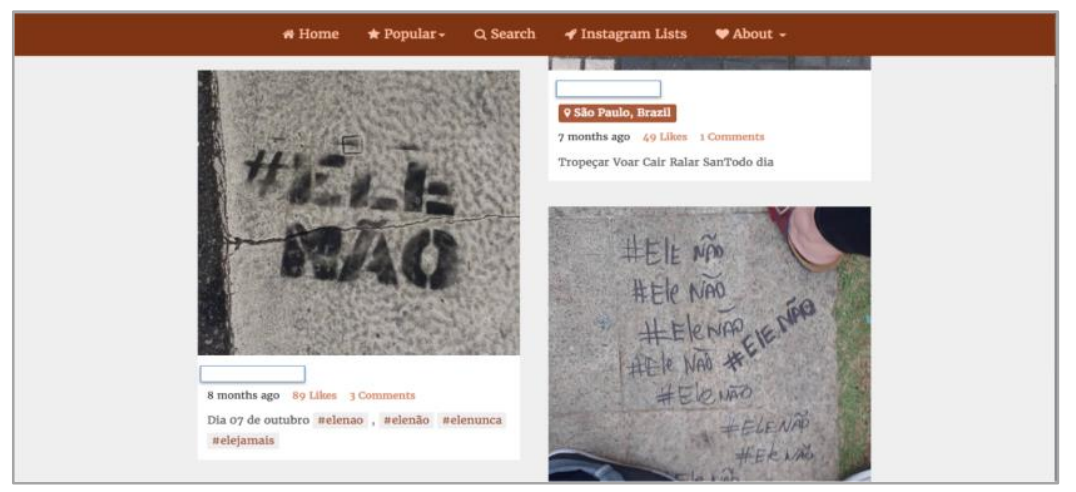

\footnotetext{
${ }^{13}$ Especificamente as figuras 4, 6 e 7, apresentadas anteriormente.

${ }^{14}$ Disponível em: <https://pikram.com/tralalajr>. Acesso em: 10 out. 2020.
} 
Figura 8 - Twitter ${ }^{15}$

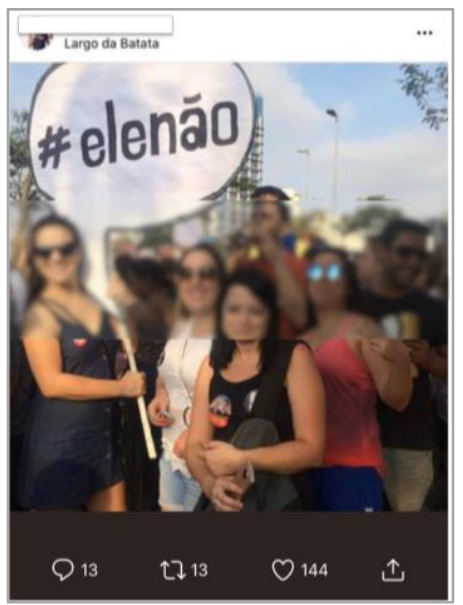

Figura 9 - Instagram ${ }^{16}$

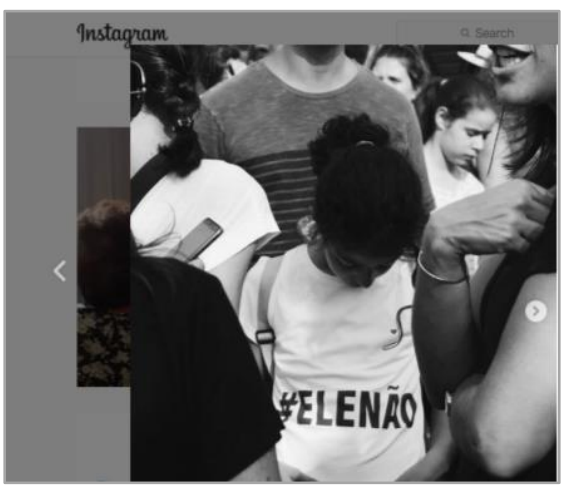

Esses grafites, pichações, cartazes e camisetas, produzidos e circulados no espaço urbano, retornam para o ambiente digital por meio de fotografias do texto que são publicadas em perfis nas redes sociais, deslanchando um processo de iconização do texto (GUNTHERT, 2015). O estatuto perceptivo e seu impacto na experiência semiótica varia de acordo com o mídium no qual são (re)produzidos, portanto a materialidade visual constrói diferentes sentidos e percepções de acordo com o espaço no qual circula, espaços estes conectados e não apartados, conforme Dias (2018) aponta.

\section{Observações finais}

Procuramos, destarte, refletir brevemente neste artigo sobre como as inscrições urbanas podem ser pensadas na sua relação com os movimentos sociais digitais, na medida em que inscrevem tecnodiscursos no espaço urbano, que posteriormente retornam ao digital. Sublinhando o papel da hashtag nesse processo, objetivamos demonstrar como, "de modo abstrato, on-line e off-line podem ser consideradas separadamente, mas, da perspectiva discursiva on-line e off-line estão materialmente ligados" (DIAS, 2016, p. 171).

Dessa maneira, centramos nosso olhar na análise do hashtagativismo, de acordo com duas práticas: a) a inserção do símbolo hashtag, nativo da web, nos grafites e/ou pichações, o que estabelece um diálogo direto entre as práticas de mobilização digital e urbana; b) a

\footnotetext{
${ }^{15}$ Disponível em: <https://twitter.com/MariluPamc/status/1371980776959528961/photo/1〉. Acesso em: 20 mar. 2021.

${ }^{16}$ Disponível em: <https://www.instagram.com/p/CMtBgwYjazu/>. Acesso em: 23 mar. 2021.
} 
apreensão e circulação na web destas inscrições urbanas por meio de fotografias, a partir do processo de iconização do texto.

Ambas as práticas, uso de hashtag nas inscrições urbanas, fotografia delas e posterior circulação na web, parecem testemunhar o diálogo cada vez mais fluido e sem fronteiras delimitadas entre o espaço digital e o espaço urbano, corroborando também a compreensão de espaço híbrido Castells (2017), no qual os movimentos sociais contemporâneos desenvolvem seus materiais e seu processo argumentativo. De acordo com o sociólogo,

em nossa sociedade, o espaço público dos movimentos sociais é construído como espaço híbrido entre as redes sociais da internet e o espaço urbano ocupado: conectando o ciberespaço com o espaço urbano numa interação implacável e construindo, tecnológica e culturalmente, comunidades instantâneas de prática transformadora (CASTELLS, 2017, p. 26).

Os grafites e as pichações democratizados no espaço urbano, bem como o uso da hashtag em cartazes, projeções e camisetas, estão à disposição dos/as cidadãos/ãs para que deles se apropriem. Eles/as por sua vez, inseridos/as também no espaço digital, expõem e fazem circular suas reivindicações levando essas hashtags do espaço urbano, agora iconizadas, a participar do ambiente da internet. Reinseridas no ambiente digital, essas hashtags iconizadas podem ser, por exemplo, postadas nas redes sociais, compartilhadas e serem alvo de comentários, conforme o conceito de ampliação (PAVEAU, 2017).

O espaço urbano e o espaço digital pertencem, portanto, à percepção de um mesmo ambiente conectado, daí a compreensão dos militantismos, não só os feministas, como partícipes de um espaço híbrido (CASTELLS, 2017), no qual os diversos regimes de significação coconstroem as formas argumentativas do ativismo contemporâneo, conectando não só os sujeitos, mas também os diversos espaços, suportes e discursividades. Além disso, vimos brevemente o potencial de uma hashtag em se rearticular e transitar novamente no espaço social, como ocorre com a \#elenão - produzida e com ápice de circulação em 2018 contra a candidatura de Bolsonaro -, que agora em meio à crise sanitária, política e social que vive o Brasil, compõe novamente o cenário digital, mas também o espaço urbano, fazendo ecoar, via memória discursiva, a palavra de ordem: \#elenão!

\section{Referências}

ALVES, Branca M.; PITANGUY, Jacqueline. O que é feminismo. Coleção Primeiros Passos. São Paulo: Brasiliense, 1991. 
BUTLER, Judith. Corpos em aliança e a política das ruas. Notas para uma teoria performativa de assembleia. Tradução Fernanda Siqueira Miguens. Rio de Janeiro: Civilização Brasileira, 2019.

CASTELLS, Manuel. La galaxia Internet. Barcelona: Plaza\&Janés Editores S.A., 2001.

CASTELLS, Manuel. Redes de indignação e esperança: movimentos sociais na internet. Tradução Carlos Alberto Medeiros. Rio de Janeiro: Zahar, 2017.

CORREA, Thiago. M. Inscrições urbanas: abordagem semiótica. 2016. 213f. Tese (Doutorado em Semiótica e Linguística Geral) - Faculdade de Filosofia, Letras e Ciências Humanas, Departamento de Linguística, Universidade de São Paulo, USP, 2016.

DEIBERT, Ronald. J. International plug'n play? Citizen activism, the Internet, and the global public policy. International Studies Perspectives, v. 1, n. 3, p. 255-272, 2000. DOI: https://doi.org/10.1111/1528-3577.00026

DIAS, Cristiane. A materialidade da mobilidade urbana: espaço, tecnologia e discurso. Línguas e Instrumentos linguísticos - n. 37, jan-ju 2016.

DIAS. Cristiane. Análise do discurso digital: sujeito, espaço, memória e arquivo. Campinas: Pontes, 2018.

FOUGEYROLLAS-SCHWEBEL, Dominique. Movimentos feministas. In: HIRATA, H. et al. (orgs.) Dicionário crítico do feminismo. São Paulo: Editora UNESP, 2009.

GUNTHERT, André. L'image partagée. La photographie numérique. Paris: Éditions Textuel, 2015.

HIRATA, Helena et al. (org.) Dicionário crítico do feminismo. São Paulo: Editora UNESP, 2009.

LÉVY, Pierre. Cibercultura. São Paulo: Editora 34, 1999.

MAINGUENEAU, Dominique. Novas tendências em Análise do Discurso. Campinas: Pontes, 1997.

OLIVEIRA, Jussara R.; MELLO, Lívia C.; RIGOLIN, Camila C. Participação feminina na pesquisa sobre tecnologia da informação no Brasil: grupos de pesquisa e produção científica de teses e dissertações. Cadernos Pagu, Campinas, n. 58, 2020. Disponível em: <https://www.scielo.br/scielo.php?script=sci_arttext\&pid=S0104-83332020000100503>.

Acesso em: 3 jan. 2021. DOI: https://doi.org/10.1590/18094449202000580004

PAVEAU, Marie-Anne. L'Analyse du discours numérique. Dictionnaire des formes et des pratiques. Paris: Hermann, 2017. [Tradução brasileira: Julia Lourenço Costa e Roberto Leiser Baronas (org.). Campinas: Pontes, 2021 (no prelo)]. 
PAVEAU, Marie-Anne. Feminismos 2.0. Usos tecnodiscursivos da geração conectada. Tradução Julia Lourenço Costa In: COSTA, J. L.; BARONAS, R. L. Feminismos em convergências: discurso, internet e política. Portugal: Grácio Editor, 2020 [2017a] ${ }^{17}$.

PINSKY, Carla B.; PEDRO, Joana. M. (orgs.). Nova história das mulheres no Brasil. São Paulo: Contexto, 2018.

TIBURI, Marcia. Feminismo em comum. Para todas, todes e todos. Rio de Janeiro: Rosa dos tempos, 2019.

VAN ENIS, Nicole. Féminismes pluriels. Bruxelles: Les Éditions Aden, 2012.

Recebido em: 1 de fevereiro de 2021

Aceito em: 22 de março de 2021

17 Tradução de: PAVEAU, Marie-Anne. Féminismes 2.0. Usages technodiscursifs de la génération connectée. Argumentation et Analyse du Discours (online), v. 18. 2017. Online desde 14 abril de 2017. Disponível em: <http://journals.openedition.org/aad/2345>. DOI : 10.4000/aad.2345. 